Cassia Ayumi Takahashi

ASSIMILAÇÃO DO NITROGÊNIO EM FOLHAS DE Vriesea gigantea (BROMELIACEAE) DURANTE A TRANSIÇÃO ONTOGENÉTICA DO HÁBITO ATMOSFÉRICO PARA O EPÍFITO COM TANQUE

São Paulo 
Cassia Ayumi Takahashi

\section{ASSIMILAÇÃO DO NITROGÊNIO EM FOLHAS DE Vriesea gigantea (BROMELIACEAE) DURANTE A TRANSIÇÃO ONTOGENÉTICA DO HÁBITO ATMOSFÉRICO PARA O EPÍFITO COM TANQUE}

Orientadora: Profa. Dra. Helenice Mercier

Departamento de Botânica do Instituto de Biociências, Universidade de São Paulo

Co-orientador: Prof. Dr. Rafael Silva Oliveira

Departamento de Biologia Vegetal, Universidade Estadual de Campinas

Tese apresentada ao Instituto de Biociências da Universidade de São Paulo, para a obtenção de Título de Doutor em Ciências, na Área de Botânica, Fisiologia Vegetal.

São Paulo 
Takahashi, Cassia Ayumi

Assimilação do nitrogênio em folhas de Vriesea gigantea (Bromeliaceae) durante a transição ontogenética do hábito atmosférico para o epífito com tanque Total de 112 páginas

Tese (Doutorado) - Instituto de Biociências da Universidade de São Paulo. Departamento de Botânica.

1. Bromeliaceae 2. Bromélia epífita atmosférica 3. Bromélia epífita com tanque 4.

Nutrição nitrogenada 5. Metabolismo do nitrogênio

I. Universidade de São Paulo. Instituto de Biociências. Departamento de Botânica.

Apoio de fomento: Coordenação de Aperfeiçoamento de Pessoal de Nível Superior (CAPES)

\section{Comissão Julgadora:}

Prof(a). Dr(a).

Prof(a). Dr(a).

Prof(a). Dr(a).

Orientador(a)
$\overline{\operatorname{Prof}(a)} \overline{\operatorname{Dr}(a) .}$

Prof(a). Dr(a).

Prof(a). Dr(a)

Corientador(a) 
Dedico esta tese a Thiago, Irene, Nelson e aos meus amigos O carinho, suporte e respeito de vocês foram essenciais para o desenvolvimento e conclusão deste trabalho! 
"The motive power is the cause of all life." Leonardo da Vinci 


\section{Agradecimentos}

Dedico meus sinceros agradecimentos a $\ldots$

$\Upsilon$ Dra. Helenice Mercier pelos importantes ensinamentos, orientação adequada, apoio firme, grande incentivo, boa amizade e dedicação sincera durante todo o processo do desenvolvimento de meus trabalhos. Agradeço profundamente pelas diversas oportunidades profissionais concedidas, os quais foram muito importantes para meu amadurecimento profissional. Muito obrigada pela enorme paciência em me orientar mais uma vez e me auxiliar em tudo o que fosse possível para se desenvolver com sucesso esse trabalho. Por fim, obrigada por me respeitar e me dar a liberdade para poder desenvolver minhas ideias e explorar minha curiosidade nesta pesquisa.

$\Upsilon$ Dr. Rafael Silva Oliveira pelos ensinamentos sobre as técnicas de isotopia, orientação adequada e grande incentivo dado durante o desenvolvimento desse estudo. Agradeço profundamente os diversos momentos em que se dedicou para discutirmos o delineamento desse projeto e o enorme esforço que fez para me auxiliar da melhor maneira possível na interpretação dos dados de isotopia. Muito obrigada pela amizade e por todas as palavras de apoio que me dedicou em vários momentos. Saiba que elas foram muito importantes para que eu recuperasse minhas forças e continuasse caminhando até a conclusão desse trabalho.

$\Upsilon$ Camila A. Cambuí pelas sugestões, idéias, apoio, auxílio e enorme amizade. Embora você estivesse morando em outro país, seu apoio foi extremamente importante para mim durante todo o doutorado. Obrigada pelas conversas através de mensagens ou pelo skype nos diversos momentos difíceis que tive que enfrentar durante esse trabalho.

$\curlyvee$ Aline Tiemi pelo auxílio e sugestões dadas nas diversas etapas desse trabalho. Obrigada principalmente pela agradável companhia durante o dia, a tarde e, principalmente, a noite e nas várias madrugadas que precisei trabalhar em meus experimentos. Agradeço a preocupação constante e as longas conversas alegres no laboratório. Todo o percurso que caminhei durante o desenvolvimento desse trabalho certamente não teria sido tão prazeroso sem a sua companhia!

$\Upsilon$ Rafael Zuccarelli pelo auxílio nas diversas madrugadas de trabalho constante aos quais tive que me dedicar durante esse estudo. Agradeço profundamente o apoio, as sugestões dadas e a preocupação constante com o meu bem estar. Muito obrigada pela amizade sincera, pelas longas conversas alegres e pela preciosa companhia no laboratório! 
$\Upsilon$ Alejandra, Paulo Mioto, Paulo Marcelo, Leonardo, Paula, Ilton, Carol, Nielda, Bruna, Lucas, Aline Bertinatto, Alessandra, Fillipe e Bruno pelo auxílio essencial nas diversas coletas dos experimentos que foram desenvolvidos nesse trabalho. Sem a ajuda de todos vocês, esse estudo jamais teria se concretizado. Agradeço sinceramente por terem me ajudado a alcançar o objetivo desse projeto. Muito obrigada pelo apoio, amizade e momentos de grande alegria e prazer.

$\curlyvee$ Dr. Marcos S. Buckeridge pela permissão do uso do liofilizador que foi essencial para a secagem das amostras relativas às análises de abundância isotópica de ${ }^{15} \mathrm{~N}$. Agradeço também às técnicas de seu laboratório, Vivi e Egle, pelo auxílio durante todo o procedimento de manuseio desse equipamento.

$\curlyvee$ Dr. Luciano Freschi e sua esposa Maria Aurineide Rodrigues pelo apoio, auxílio, conselhos, sugestões, ideias e ensinamentos. Agradeço profundamente a amizade e o apoio dado durante o desenvolvimento desse trabalho. Obrigada principalmente pela hospedagem em sua casa ou em sua sala de trabalho em muitos momentos que tive que trabalhar durante a madrugada.

Dr. Gilberto B. Kerbauy pelo auxílio e permissão do uso da casa de vegetação do IBUSP para a criação e manutenção das bromélias utilizadas nesse trabalho.

$\curlyvee$ Ana Maria, Willian, Rita e Cinthia por manterem sempre as boas condições necessárias no laboratório para a realização dos meus experimentos. Obrigada por me auxiliarem em diversas atividades desse trabalho. Agradeço a amizade, boa companhia e pelos momentos alegres de convívio.

$\Upsilon$ Erismaldo que proporcionou as condições necessárias para o cultivo adequado das bromélias de acordo com os tratamentos propostos nesse trabalho, bem como o auxílio nos cuidados de manutenção diária das bromélias durante os momentos em que estive ausente no jardim.

$\Upsilon$ Thiago, Irene e Nelson pelo carinho, amor, respeito e suporte durante essa etapa da minha vida.

$\curlyvee$ Todos os amigos e colegas do Laboratório de Fisiologia Vegetal do IBUSP e do Departamento de Botânica que me proporcionaram tantos momentos alegres e divertidos. Obrigada pelo apoio, carinho, respeito e grande amizade construída com sinceridade. $\mathrm{O}$ caminho não teria sido tão prazeroso sem a presença de vocês.

$\Upsilon$ Todos os funcionários do Departamento de Botânica que de alguma forma proporcionaram condições importantes para a realização desse trabalho.

$\Upsilon$ CAPES por conceder a bolsa de doutorado e seus benefícios. 